\title{
Does knowledge brokering improve the quality of rapid review proposals? A before and after study
}

\author{
Gabriel Moore ${ }^{1,2^{*}}$ (D), Sally Redman², Catherine D'Este ${ }^{3}$, Steve Makkar ${ }^{2}$ and Tari Turner ${ }^{4}$
}

\begin{abstract}
Background: Rapid reviews are increasingly being used to help policy makers access research in short time frames. A clear articulation of the review's purpose, questions, scope, methods and reporting format is thought to improve the quality and generalisability of review findings. The aim of the study is to explore the effectiveness of knowledge brokering in improving the perceived clarity of rapid review proposals from the perspective of potential reviewers. To conduct the study, we drew on the Evidence Check program, where policy makers draft a review proposal (a pre knowledge brokering proposal) and have a 1-hour session with a knowledge broker, who re-drafts the proposal based on the discussion (a post knowledge brokering proposal).

Methods: We asked 30 reviewers who had previously undertaken Evidence Check reviews to examine the quality of 60 pre and 60 post knowledge brokering proposals. Reviewers were blind to whether the review proposals they received were pre or post knowledge brokering.

Using a six-point Likert scale, reviewers scored six questions examining clarity of information about the review's purpose, questions, scope, method and format and reviewers' confidence that they could meet policy makers' needs. Each reviewer was allocated two pre and two post knowledge brokering proposals, randomly ordered, from the 60 reviews, ensuring no reviewer received a pre and post knowledge brokering proposal from the same review.

Results: The results showed that knowledge brokering significantly improved the scores for all six questions addressing the perceived clarity of the review proposal and confidence in meeting policy makers' needs; with average changes of 0.68 to 1.23 from pre to post across the six domains.

Conclusions: This study found that knowledge brokering increased the perceived clarity of information provided in Evidence Check rapid review proposals and the confidence of reviewers that they could meet policy makers' needs. Further research is needed to identify how the knowledge brokering process achieves these improvements and to test the applicability of the findings in other rapid review programs.
\end{abstract}

Keywords: Knowledge brokering, Rapid reviews, Commissioned rapid reviews, Review literature as topic, Knowledge synthesis, Evidence summaries, Research utilisation, Policy-relevant

\footnotetext{
* Correspondence: gabriel.moore@saxinstitute.org.au

'School of Public Health, Sydney Medical School, The University of Sydney,

Edward Ford Building (A27), Sydney, NSW 2006, Australia

${ }^{2}$ The Sax Institute, Level 13, Building 10, 235 Jones Street, Ultimo, NSW 2007,

Australia

Full list of author information is available at the end of the article
} 


\section{Background}

The use of evidence from research in the development of health policy has the potential to inform decision-making and improve health outcomes. However, it is widely recognised that many opportunities to use research are currently missed $[1,2]$.

Policy makers and program managers have reported barriers and facilitators to using research evidence in policy-making [3, 4]. For example, a recent systematic review found that the most frequently reported barriers to the use of evidence were poor access to good quality, relevant research and a lack of timely research output [5]. Policy makers also point to a number of strategies they think might work to increase their use of research. In particular, they have identified the need to improve access to summaries, reviews and syntheses of research $[1,5,6]$.

Rapid reviews of research can improve timely access to relevant research for decision-making. Rapid reviews provide information about what evidence exists, where there are gaps in the evidence, an evaluation of the quality of the evidence and the researchers' understanding of the implications of this evidence for policy-making [7, 8].

Rapid review programs are increasingly being implemented. For example, in Canada, the Knowledge to Action research program provides rapid reviews of research in Ottawa [9, 10], and the McMaster Health Forum provides rapid response documents on 10- or 30-day time frames [11, 12]. In UK, the Government Social Research Service enables commissioned rapid evidence assessments [13, 14], and the King's Fund produces rapid evidence reviews [15]. In USA, the Veterans Affairs Evidence-based Synthesis Program [16, 17] and the Agency for Healthcare Research and Quality's Evidence-based Practice Centers [18] produce syntheses of targeted health care topics of particular importance to policy makers and managers. Furthermore, Cochrane Innovations provides rapid reviews to support evidenceinformed decision-making for policy makers and healthcare professionals [19].

There is growing interest in how such reviews might be made as useful as possible [6, 9]. Reviewers need a clear understanding of policy makers' requirements to provide useful reviews $[6,9,20]$. Early studies point to the importance of a clear articulation of the review's purpose, questions, scope and methods [9, 21, 22]. These factors have been argued to improve the quality and generalisability of rapid review findings [22].

In contrast to systematic reviews, rapid reviews are frequently commissioned in response to questions arising from immediate policy processes [23]. Review findings are therefore intended to address a particular policy issue, in a specific context and time. If a rapid review is to be useful, understanding how a policy issue arose and the policy maker's purpose in commissioning the review will be important [21, 24]. The purpose of the review will inform the review questions, scope, methods and format.

The task of translating policy questions into specific questions that can be addressed through a rapid review is surprisingly complex [20]. The review questions must be appropriate both from a policy perspective (reflecting the subject matter and focus of the review) and from a research perspective (be amenable to research processes such as defining search terms and inclusion criteria). A clear scope for a rapid review should 'set boundaries' and define key terms [20] so they are consistent with the policy makers' intent and provide guidance for the reviewers in terms of their search strategy, screening of papers, data extraction and analysis. Ideally, the scope of the review is identified at the outset between the policy agency and the reviewer and outlines inclusion and exclusion criteria, evidence sources and timelines, and the geographic boundaries and languages of the review.

The need for transparent reporting of rapid review methods has been acknowledged [20, 22]. A variety of techniques have been used to make reviews more rapid, including narrowing search strategies, limiting study types, accelerating data extraction and limiting quality assessment. A clear articulation of these methods in rapid reviews is critical in determining the reliability and validity of the findings.

Despite the agreed importance of outlining a detailed scope and methods for rapid reviews [23, 25], to date, there has been only limited investigation of how this might best be done. It has been suggested that tailored and customised formats will increase the extent to which rapid reviews are useful to policy makers [6]. Standardised products may run the risk of reducing the usability of a particular report, as topic areas, review questions and policy contexts vary considerably across and within agencies.

Knowledge brokering has frequently been proposed as a strategy to increase the use of research in policymaking $[23,25]$. Knowledge brokers have been described as skilled communicators whose extensive experience in both policy and research enables their unique capacity to work within and across policy and research contexts [25-27]. Knowledge brokering is thought to facilitate access to research and research findings [28], assist in translating research into policy [29, 30], harness the expertise of policy makers and researchers, and sustain their ongoing engagement $[31,32]$. Knowledge brokering has been used at the interface between policy and research to clarify information needs, define researchable policy questions, commission syntheses of research and report on their findings [33, 34]. However, little is known about the impact of knowledge brokering in practice. We found only one study which tested the impact of 
knowledge brokering on the use of research by policy makers and, though there were benefits to organisations with low levels of research receptivity, no effect overall was demonstrated in evidence-informed decision-making $[35,36]$. To date, no studies have reported on the effectiveness of knowledge brokering in commissioning rapid reviews.

The Sax Institute's Evidence Check rapid review program was developed to assist organisations gather the best and most relevant research evidence to inform their policy-making and program development. As part of the program, knowledge brokers work with a policy or program team to help them clarify their policy issue, increase the accuracy of their review questions, clarify the review scope and methods and help determine timelines, budgets and reporting formats [37]. Knowledge brokers are senior researchers with extensive experience working with policy agencies.

In the Evidence Check process, policy makers and program managers complete a draft review proposal before knowledge brokering (a pre knowledge brokering proposal), describing their policy or program issue and proposed review questions. After structured and tailored discussion with the policy team, the knowledge broker drafts a synthesis of the discussion which is agreed with the policy team (a post knowledge brokering proposal). This post knowledge brokering proposal is given to the review authors who will undertake the review, defining its parameters. To date, more than 200 reviews have been commissioned through this process. More information about the Evidence Check process can be found on the Sax Institute website [38].

The aim of the study was to explore whether knowledge brokering, undertaken as part of the Evidence Check program, improved the perceived clarity of the policy agencies' review proposals from the perspective of potential reviewers, in relation to the purpose of the review, the review questions, the scope and method, and the information to be included in the report; and improved the confidence of reviewers that they could produce a report that would meet policy makers' needs based on the information contained in the proposal.

\section{Methods}

\section{Study design}

Individuals who had previously undertaken reviews through the Evidence Check program were asked to score pre and post knowledge brokering proposals in terms of their perceived clarity; previous reviewers were selected as the study participants as we regarded their views as most likely to reflect those of other reviewers in the Evidence Check program, and we refer to them as 'representative reviewers'. Representative reviewers were blind to whether the proposal was written pre or post knowledge brokering. Thirty representative reviewers were included in the study, and each received four proposals from 120 in total, from 60 rapid reviews.

\section{Study sample}

All Evidence Check reviews commissioned between 1 January 2006 and 30 June 2013, with both a pre knowledge brokering and a post knowledge brokering proposal in a standard format were eligible for inclusion in the study. Of the 120 reviews commissioned, 85 met the inclusion criteria. Sixty reviews were randomly selected, giving a total sample of 120 proposals: 60 pre knowledge brokering and 60 post knowledge brokering. All proposals were presented in a uniform design and format and were randomly assigned a number from 1 to 60 . Business information, such as publication and payment arrangements, was removed from the proposals.

Seventy-seven first authors of reviews previously commissioned through the Evidence Check program were invited to participate in the study, as representative of potential reviewers. The first 30 representative reviewers to respond were randomly assigned a unique identification number (numbered 1-30) by a research assistant not otherwise involved in this study, ensuring that the study authors were blinded to the identity of the representative reviewers.

\section{Allocation of reviews}

Each representative reviewer was allocated two pre and two post knowledge brokering proposals in sequential order so they did not receive pre and post proposals from the same review, and with the restriction that they did not receive a proposal for a review they had undertaken. For example, representative reviewer 1 was allocated pre knowledge brokering proposals from reviews 1 and 2 and post knowledge brokering proposals from reviews 3 and 4; representative reviewer 2 was allocated pre knowledge brokering proposals from reviews 3 and 4 and post knowledge brokering proposals from reviews 5 and 6 and so on. The last representative reviewer (representative reviewer 30) was allocated pre knowledge brokering proposals from reviews 59 and 60, and post knowledge brokering proposals from reviews 1 and 2. Representative reviewers were blind to whether the proposals they received were pre or post knowledge brokering. Each representative reviewer scored four proposals, and each proposal was scored once.

Representative reviewers were given 1 month to score the proposals and were sent up to three reminder emails. Each representative reviewer scored each proposal on six questions, using the perception of proposal questions described below. 


\section{The perception of proposal questions}

Two study authors (GM and TT) developed questions designed to capture the perceptions of representative reviewers about the clarity of the main components of the proposals and about their confidence that they could conduct a review based on the information in the proposals. The questions about clarity were formulated using the standard headings in the Cochrane Handbook >for Systematic Reviews of Interventions (http://hand book.cochrane.org/) as a starting point. Respondents were given the following response options using a Likert scale approach. The response options ranged from 'very unclear/very unconfident' to 'very clear/very confident'. We refer to these questions as the perception of proposal questions throughout. The perception of proposal questions were examined by three individuals not participating in the main study but with the same characteristics as the representative reviewers. Each individual was asked to indicate their preferred version of the scale and was interviewed about the clarity, appropriateness and relevance of the questions as proposed by Holden [39]. The individuals were able to complete all the perception of proposal questions and indicated that they found the questions clear and easy to use. Based on the results of the pilot testing, the questionnaire was reduced in length for feasibility, and ease of use and minor amendments were made to the instructions for representative reviewers. The questionnaire was restructured to capture the main content areas only, resulting in five questions about the clarity of information; a sixth question was added about representative reviewers' confidence, and a seventh optional question allowed them to comment on their experience of scoring the proposals. An example of the perception of proposal questions is provided in Additional file 1.

The final perception of proposal questions included the following questions: (1) How clear is the proposal about why the policy maker is commissioning the review? (2) How clearly articulated are the questions to be answered in this review? (3) How clearly described is the scope of the review? (4) How clearly described is the method of the review? (5) How clear is the proposal about what should be included in the report? (6) Based on the information provided in the proposal, how confident are you that a researcher in this field will know enough to provide a rapid review of the literature that will meet the policy maker's needs? (7) Is there anything else you would like to tell us? Respondents were required to answer these questions based on the material in the proposal.

\section{Data analysis}

The data were analysed using Stata version 13. For each question, a mixed model was generated with crossed effects for review and representative reviewer both at level $2[40,41]$. Specifically,pre and post proposals $(n=$ $120)$ were nested within both reviews $(n=60)$ and representative reviewers $(n=30)$, but the reviews were not nested within representative reviewers. A pre/post variable which was statistically significantly different from 0 indicated that there was a significant change in score from pre to post knowledge brokering. The analysis used a random effects model, which is valid under the assumptions that data are missing at random, conditional on the covariates included in the model. The reviewer, the proposal and the score were all included in the analysis, to manage any issues associated with missing values.

A sample size of 60 reviews and 30 representative reviewers would allow us to detect a difference in outcomes from pre to post knowledge brokering of approximately half a standard deviation, with $80 \%$ power, a 5\% significance level, a pre-post score correlation of 0.4 or more and a design effect of 1.5 due to correlation of observations within representative reviewers. We considered this pre-post difference to be a clinically important difference in the quality of the proposals.

Illustrative examples were selected by one of the study authors (GM) from the proposals; permission was sought from the relevant agencies for inclusion of the examples where possible, and otherwise, all identifying information was removed.

The dataset supporting the conclusions of this article is included within the article and its Additional file 2 .

\section{Results}

Ninety-eight of the 120 documents were returned (82\%). Of these, 82 documents were pre and post from the same review, and 16 were either pre or post documents only (eight pre and eight post). Five representative reviewers returned no documents ( $n=20$ missing), and two representative reviewers returned three out of four documents ( $n=2$ missing).

\section{Quantitative analysis}

Table 1 shows the mean, standard deviation and effect size for changes from the pre to post knowledge brokering scores.

The mean scores were significantly higher for the post knowledge brokering proposals compared to that for pre knowledge brokering proposals for all six questions. The mean difference in scores from pre to post knowledge brokering ranged from 0.68 for question 4 to 1.23 for question 3, after adjusting for review and representative reviewer (see Table 1). 
Table 1 Mean and standard deviation of pre and post knowledge brokering scores for each domain

\begin{tabular}{|c|c|c|c|c|c|c|c|c|}
\hline & \multicolumn{2}{|c|}{$\begin{array}{l}\text { Pre knowledge } \\
\text { brokering }\end{array}$} & \multicolumn{2}{|c|}{$\begin{array}{l}\text { Post knowledge } \\
\text { brokering }\end{array}$} & \multicolumn{4}{|c|}{$\begin{array}{l}\text { Change from pre to post knowledge } \\
\text { brokering }\end{array}$} \\
\hline & \multirow[t]{2}{*}{ Mean } & \multirow[t]{2}{*}{ SD } & \multirow[t]{2}{*}{ Mean } & \multirow[t]{2}{*}{ SD } & \multirow[t]{2}{*}{$\overline{\text { Mean }^{a}}$} & \multicolumn{2}{|c|}{$\begin{array}{l}\text { 95\% confidence } \\
\text { limits }\end{array}$} & \multirow[t]{2}{*}{$p$} \\
\hline & & & & & & Lower & Upper & \\
\hline Clarity about why the review was commissioned & 4.67 & 1.46 & 5.37 & 0.95 & 0.681 & 0.249 & 1.114 & 0.002 \\
\hline Clarity of the review questions & 4.47 & 1.39 & 5.22 & 1.01 & 0.755 & 0.282 & 1.228 & 0.002 \\
\hline Clarity of the scope & 3.92 & 1.41 & 5.16 & 1.08 & 1.228 & 0.816 & 1.641 & $<0.001$ \\
\hline Clarity of the method & 3.883 & 1.32 & 4.55 & 1.28 & 0.669 & 0.308 & 1.029 & $<0.001$ \\
\hline Clarity of the report inclusions & 4.35 & 1.35 & 5.37 & 0.78 & 1.026 & 0.612 & 1.439 & $<0.001$ \\
\hline Reviewers' confidence & 3.84 & 1.30 & 4.86 & 1.19 & 1.018 & 0.537 & 1.500 & $<0.001$ \\
\hline
\end{tabular}

${ }^{a}$ Note that the estimate represents the mean change from pre to post (post score-pre score), i.e. a positive value indicates that the post knowledge brokering score is higher than the pre knowledge brokering score

$p$ value from Wald test

\section{Description of changes following knowledge brokering}

The mean score for perceived clarity about why the review was commissioned changed from 4.67 to 5.37 following knowledge brokering. Pre knowledge brokering proposals often lacked the details representative reviewers needed to provide a review which would be relevant and useful. They included statements such as 'the purpose of the review is to inform the agency's planning and implementation' or 'the review will inform the design of a new model of care'. Post knowledge brokering, additional information was provided about how the review would be used and by whom. For example, 'The review will be used to develop a model of care for improved funding and delivery of [service type] services in hospital and community settings in NSW. The review will also be used in a consultative process to achieve a consensus view among clinicians on the model of care. The audience for this review therefore includes senior policy makers within the [policy agency] and clinicians involved in service planning and care delivery.'

In this study, the mean score for clarity of scope changed from 3.92 to 5.16 following knowledge brokering. The majority of proposals, written pre knowledge brokering, provided only limited information such as data sources or years. Examples of scope pre knowledge brokering included 'Reviewers should search academic databases, and the grey literature' or 'the target population is adults'. Post knowledge brokering, much more detail was provided about the policy makers' focus of interest. One example of this was 'The review should focus on changes in [service type] and in [population subgroups] such as children, adolescents, older people, [age ranges specified], those living outside major metropolitan areas, or those from culturally and linguistically diverse backgrounds. To be relevant, the included evidence must provide details of the context in which the change in [service type] was implemented, such as organisational models, funding models, cultural context, political context, health workforce, or governance structures. While evidence from Australian jurisdictions is preferred, evidence from other countries with similarly advanced healthcare systems is applicable (for example, UK, Western Europe, Canada, USA, New Zealand).'

Mean scores in this study about the perceived clarity of the methods changed from 3.88 to 4.55 following knowledge brokering. Most pre knowledge brokering proposals in our study provided only general statements such as 'the reviewer should comment on the quality of the findings' or 'the report should include tables of the relevant papers indicating the methods and findings'. Post knowledge brokering an example read 'The review should provide a brief summary of existing reviews of the evidence, including clinical guidelines, with an expert recommendation, and analysis of the applicability of the findings to NSW. The reviewer should include opinion about the quality and strength of the findings and identify the gaps in the evidence, including studies with insufficient data and/or low quality methodology for measuring an effect size. In assessing the quality of the included studies, the reviewer may use existing quality assessment guidelines (such as that issued by the NHMRC), or define a scale (e.g. weak/moderate/strong).'

\section{Discussion}

This study found significant improvements, following knowledge brokering, in the perceived clarity of information provided in Evidence Check rapid review proposals about their purpose, review questions, scope, method, and report format, and in representative reviewers' confidence that they could meet policy makers' needs. These differences remained even after controlling for representative reviewer and reviews.

The examples provided demonstrate the ways in which often very loosely defined questions were refined, expanded and clarified to provide much more contextual information and direction for the representative reviewer following discussion with the knowledge broker. 
The role of knowledge brokers in our study differs from those of other studies in some important ways. For example, the work of knowledge brokers often focuses on developing the research capacity of policy makers or on supporting agencies to apply research in policies and programs [35]. Knowledge brokering interventions are often multi-faceted and may be sustained for periods of months or years [30]. In contrast, this study demonstrates that knowledge brokering may also be effective in one-off, brief interventions.

The study design ensured that representative reviewers were randomly assigned documents with the restriction that they could not receive a pre and post knowledge brokering proposal from the same review and were blinded to the proposals' pre or post knowledge brokering status. Representative reviewers participating in the study were authors of Evidence Check rapid reviews and will have evaluated the proposals from the 'real-world' perspective of reviewers conducting the reviews. Further, the study had a larger sample size than the previous studies (60 reviews compared to 11 reviews [9]) and used a multi-level analysis (Fig. 1) that adjusted for the crossed effects of review and representative reviewer.

The findings of this study indicate that representative reviewers believe that review proposals are considerably clearer after knowledge brokering. The illustrative text from proposals provide some examples of the major changes to the descriptions of what is required following the knowledge brokering. On average, the cost of the knowledge brokering session is around \$1500 (AUD) adding about $5 \%$ to the overall cost of reviews produced through Evidence Check. Subjectively, policy agencies often comment very positively about the value provided by the knowledge brokering; as one policy maker commented: 'The knowledge broker was very good at quickly understanding the policy issues that we were trying to address; she could very quickly grasp that and was then able to help us define our research questions' [37]. Indeed many first time users of the Evidence Check program report commissioning subsequent reviews because of the knowledge brokering process. Although it is beyond the scope of the current study, additional work using discrete choice experiments is planned to explore the willingness of policy makers to pay for components such as knowledge brokering [42].

This study has several limitations. Evidence Check uses a standardised process that may be different from those of the other rapid review programs, and knowledge brokering may differentially affect those review proposals. While our study controlled for the effect of reviews and representative reviewers, there may be other factors at work that were not identified in our study. We do not know whether reviews commissioned using other methods would have provided less relevant information, nor can we be certain that the reported changes in clarity actually result in more timely, relevant or useful reports for policy makers. We went to considerable lengths to remove any indication of whether the proposal was pre or post knowledge brokering, and informal comments suggested that it was not obvious to some representative reviewers. Although it remains possible that some representative reviewers were able to guess whether they were reviewing a pre or post knowledge brokering proposal, it is not clear that this would result in a significant response bias; that is, even if representative reviewers guessed the status of the proposal, they would have little reason for grading post proposals more favourably than pre proposals. Further, the examples described above clearly demonstrate the kinds of improvements in clarity that were observed after knowledge brokering, suggesting the findings are not artefactual.

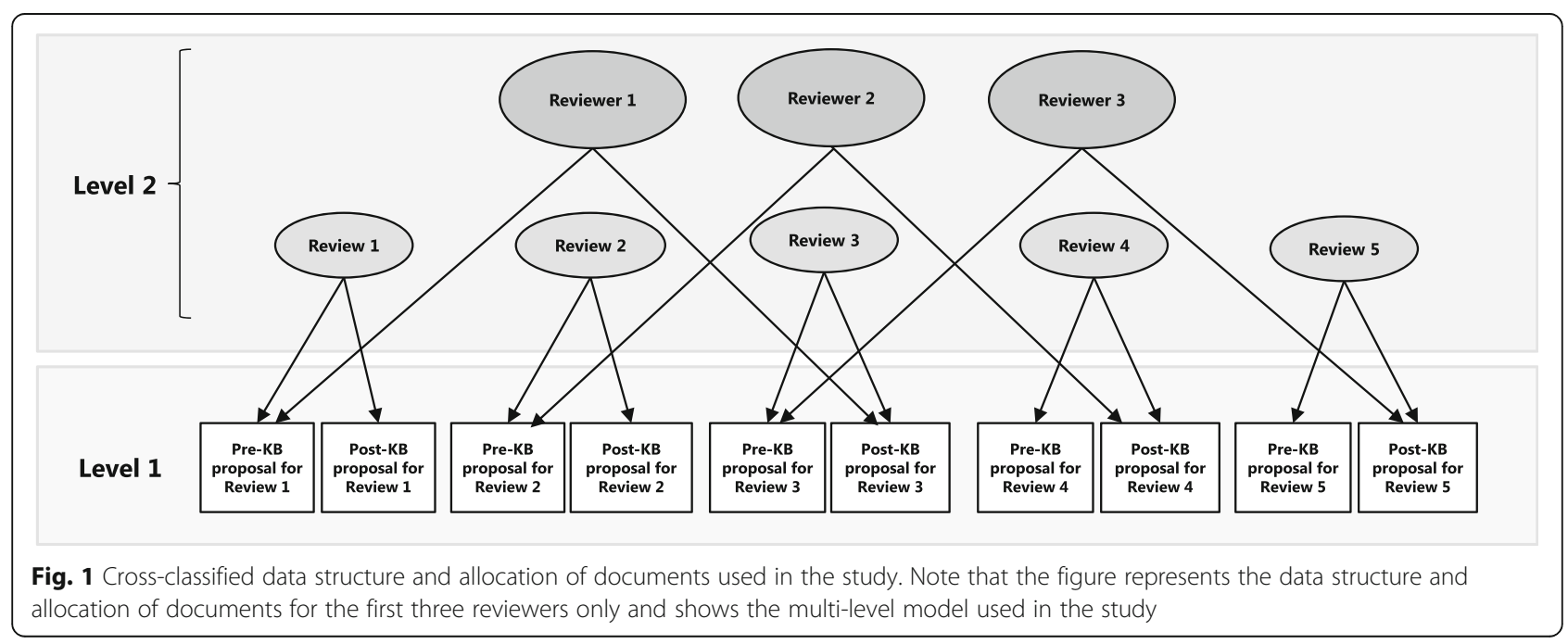


This paper examined the perceptions of representative reviewers about the proposals, but we cannot comment on whether the clarity of the proposal related to the quality of the subsequent review. While it would be interesting to examine the impact on the quality of the reviews themselves, in practical terms, it would be extremely difficult because of the many factors that affect reviews in addition to the proposal. For example, the quality of the review will be affected by the skills of the researcher and the amount and quality of primary research available. Similarly, we acknowledge that we are assessing perceptions of clarity; however, the representative reviewers are experienced reviewers who might be seen as providing an accurate window into the likely views of similar reviewers in the future.

Taken together, these findings suggest that this model of knowledge brokering may be an effective strategy for other agencies wishing to commission rapid reviews and for the researchers who will undertake them. Certainly, in our study, proposals written after knowledge brokering were qualitatively different to those written before knowledge brokering. The key concepts underpinning the review had been defined: the focus and intent of the questions was clear and was matched to the user's context, the scope was narrowed and consistent with the likely available literature, the methods had been determined and the analytical framework was agreed. While some fine-tuning may be required, a researcher considering undertaking the review will have had clear information about its parameters.

\section{Conclusions}

This study found that following knowledge brokering, there was a significant increase in the perceived clarity of information provided in the Evidence Check rapid review proposals about the review's purpose, review questions, scope, method and report format, and in the confidence of the representative reviewers that they could conduct a review that would meet the policy makers' needs. Further research is needed to identify how the knowledge brokering process achieves these improvements and to test the applicability of the findings in other rapid review programs.

\section{Additional files}

Additional file 1: Perception of proposal questions for scoring by reviewers. (PDF $72 \mathrm{~kb}$ )

Additional file 2: Representative reviewers' scores. (XLSX 83 kb)

\section{Acknowledgements}

The authors acknowledge Danielle Campbell, Joanna Khoo and Tari Turner, who piloted the perception of proposal questions; Anna Williamson, Abby Haynes and Melanie Andersen for their advice; and Catherine Kellick who contributed to the allocation of documents to the representative reviewers.

\section{Funding}

GM was supported by the Outcomes, Services and Policy for the Reproductive Early Years (OSPREY) Program under the NHMRC Capacity Building Grants in Population Health and Health Services Research ID number 573122 .

\section{Availability of data and materials}

All data generated or analysed during this study are included in this published article and its supplementary information file, Additional file 2.

\section{Authors' contributions}

GM, SR, CDE and TT made a substantial contribution to the conception and design of the study, and all authors contributed to the analysis or interpretation of the data. GM drafted the manuscript with critical revision by SR, CD, SM and $\Pi$ TT. TT pilot-tested the perception of proposal questions. All authors approved the final manuscript and agree to be accountable for the work.

\section{Competing interests}

The authors declare that they have no competing interests.

\section{Consent for publication}

Not applicable.

\section{Ethics approval and consent to participate}

The ethics approval was obtained from the University of Sydney Human Research Ethics Committee reference number 2013/735 approved 10 October 2013. Participant consent forms were obtained.

Written consent was received from the policy agencies whose Evidence Check rapid reviews are published on the Sax Institute website. Permission was sought from the relevant agencies for the inclusion of the examples where possible, and otherwise, all identifying information was removed.

\section{Author details}

${ }^{1}$ School of Public Health, Sydney Medical School, The University of Sydney, Edward Ford Building (A27), Sydney, NSW 2006, Australia. ${ }^{2}$ The Sax Institute, Level 13, Building 10, 235 Jones Street, Ultimo, NSW 2007, Australia. ${ }^{3}$ National Centre for Epidemiology and Population Health (NCEPH), Research School of Population Health, The Australian National University, 62 Mills Road, Acton, ACT 0200, Australia. ${ }^{4}$ School of Public Health and Preventive Medicine, Monash University, Level 1, 549 St Kilda Road, Melbourne, VIC 3004, Australia.

Received: 18 June 2016 Accepted: 6 January 2017

Published online: 28 January 2017

\section{References}

1. Campbell DM, Redman S, Jorm L, Cooke M, Zwi AB, Rychetnik L. Increasing the use of evidence in health policy: practice and views of policy makers and researchers. Aust N Z J Public Health. 2009:6(1):21.

2. LaRocca RL. The effectiveness of knowledge translation strategies in public health. BMC Public Health. 2012;12:751.

3. de Goede J, van Bon-Martens MJ, Putters K, van Oers HA. Looking for interaction: quantitative measurement of research utilization by Dutch local health officials. Health Res Policy Syst. 2012;10(9).

4. Ellen ME, Léon G, Bouchard G, Ouimet M, Grimshaw JM, Lavis JN. Barriers, facilitators and views about next steps to implementing supports for evidence-informed decision-making in health systems: a qualitative study. Implement Sci. 2014;9(1):179.

5. Oliver K, Innvar S, Lorenc T, Woodman J, Thomas J. A systematic review of barriers to and facilitators of the use of evidence by policymakers. BMC Health Serv Res. 2014;14(1):1.

6. Ellen ME, Lavis JN, Wilson MG, Grimshaw J, Haynes RB, Ouimet M, Raina P, Gruen R. Health system decision makers' feedback on summaries and tools supporting the use of systematic reviews: a qualitative study. Evid Policy. 2014:10(3):337-59.

7. Moat KA, Lavis JN, Abelson J. How contexts and issues influence the use of policy-relevant research syntheses: a critical interpretive synthesis. Milbank Q. 2013;91(3):604-48.

8. Kastner M, Tricco AC, Soobiah C, Lillie E, Perrier L, Horsley T, Welch V, Cogo E, Antony J, Straus SE. What is the most appropriate knowledge synthesis method to conduct a review? Protocol for a scoping review. BMC Med Res Methodol. 2012;12(1):114. 
9. Khangura S, Konnyu K, Cushman R, Grimshaw J, Moher D. Evidence summaries: the evolution of a rapid review approach. Syst Rev. 2012;1:10.

10. The Ottawa Hospital Research Institute. Knowledge to Action Research Program. http://www.ohri.ca/kta/. Accessed 24 Oct 2016.

11. Wilson MG, Lavis JN, Gauvin F-P. Developing a rapid-response program for health system decision-makers in Canada: findings from an issue brief and stakeholder dialogue. Syst Rev. 2015;4:25.

12. McMaster Health Forum. Rapid Response Program. https://www. mcmasterhealthforum.org/stakeholders/rapid-response-program. Accessed 24 Oct 2016.

13. Collins AMCD, Miller J, Kirk S. The production of quick scoping reviews and rapid evidence assessments: a how to guide. London: Joint Water Evidence Group; 2015

14. United Kingdom Government Social Research Service. Rapid evidence Assessments Collection. https://www.gov.uk/government/collections/rapidevidence-assessments. Accessed 24 Oct 2016.

15. The King's Fund. Rapid Evidence Service. http://www.kingsfund.org.uk/ library. Accessed 24 Oct 2016.

16. Peterson K, Floyd N, Ferguson L, Christensen V, Helfand M. User survey finds rapid evidence reviews increased uptake of evidence by Veterans Health Administration leadership to inform fast-paced health-system decisionmaking. Syst Rev. 2016;5(1):132.

17. United States Department of Veterans Affairs. Evidence-based Synthesis Program. http://www.hsrd.research.va.gov/publications/esp/. Accessed 24 Oct 2016.

18. Agency for Healthcare Research and Quality. Evidence-based Practice Centers (EPC) program overview. http://www.ahrq.gov/research/findings/ evidence-based-reports/overview/index.html. Accessed 24 Oct 2016.

19. The Cochrane Collaboration. Cochrane Innovations. http://www.cochrane. org/about-us/cochrane-innovations. Accessed 24 Oct 2016.

20. Thomas J, Newman M, Oliver S. Rapid evidence assessments of research to inform social policy: taking stock and moving forward. Evid Policy. 2013;9(1):5-27.

21. Ganann R, Ciliska D, Thomas H. Expediting systematic reviews: methods and implications of rapid reviews. Implement Sci. 2010;5(1):56.

22. Featherstone RM, Dryden DM, Foisy M, Guise J-M, Mitchell MD, Paynter RA, Robinson KA, Umscheid CA, Hartling L. Advancing knowledge of rapid reviews: an analysis of results, conclusions and recommendations from published review articles examining rapid reviews. Syst Rev. 2015:4(1):1-8.

23. Moore G, Redman S, Haines M, Todd A. What works to increase the use of research in population health policy and programmes: a review. Evid Policy. 2011;7(3):277-305.

24. Moore G, Redman S, Turner T, Haines M. Rapid reviews in health policy: a study of intended use in the New South Wales' Evidence Check program. Evid Policy In press.

25. Hammami H, Amara N, Landry R. Organizational climate and its influence on brokers' knowledge transfer activities: a structural equation modeling. Int J Inf Manage. 2013;33(1):105-18.

26. Meagher $L$, Lyall $C$. The invisible made visible: using impact evaluations to illuminate and inform the role of knowledge intermediaries. Evid Policy. 2013;9(3):409-18.

27. Dagenais C, Laurendeau M-C, Briand-Lamarche M. Knowledge brokering in public health: a critical analysis of the results of a qualitative evaluation. Eval Program Plann. 2015;53:10-7.

28. Dwan KM, Mclnnes PC. Increasing the influence of one's research on policy. Aust Health Rev. 2013;37(2):194-8.

29. Traynor R, DeCorby K, Dobbins M. Knowledge brokering in public health: a tale of two studies. Public Health. 2014;128(6):533-44.

30. Dobbins M, Robeson P, Ciliska D, Hanna S, Cameron R, O'Mara L, DeCorby K Mercer S. A description of a knowledge broker role implemented as part of a randomized controlled trial evaluating three knowledge translation strategies. Implement Sci. 2009;4(23):1-9.

31. Urquhart R, Porter GA, Grunfeld E. Reflections on knowledge brokering within a multidisciplinary research team. J Contin Educ Health Prof. 2011;31(4):283-90

32. Long JC, Cunningham FC, Braithwaite J. Bridges, brokers and boundary spanners in collaborative networks: a systematic review. BMC Health Serv Res. 2013;13(1):1-13.

33. Canadian Health Services Research Foundation. The theory and practice of knowledge brokering in Canada's health system, vol. 25. Ottawa: Canadian Health Services Research Foundation; 2003.
34. Frost H, Geddes R, Haw S, Jackson CA, Jepson R, Mooney JD, Frank J. Experiences of knowledge brokering for evidence-informed public health policy and practice: three years of the Scottish Collaboration for Public Health Research and Policy. Evid Policy. 2012;8(3):347-59.

35. Dobbins M, Hanna SE, Ciliska D, Manske S, Cameron R, Mercer SL, O'Mara L, DeCorby K, Robeson P. A randomized controlled trial evaluating the impact of knowledge translation and exchange strategies. Implement Sci. 2009;4(1):61.

36. Bornbaum CC, Kornas K, Peirson L, Rosella LC. Exploring the function and effectiveness of knowledge brokers as facilitators of knowledge translation in health-related settings: a systematic review and thematic analysis. Implement Sci. 2015;10(1):1-12

37. Campbell D, Donald B, Moore G, Frew D. Evidence check: knowledge brokering to commission research reviews for policy. Evid Policy. 2011;7(1):97-107.

38. The Sax Institute. Evidence Check. https://www.saxinstitute.org.au/our-work/ knowledge-exchange/evidence-check/. Accessed 24 Oct 2016.

39. Holden RR. Face Validity. In: The Corsini encyclopedia of psychology. Hoboken: Wiley; 2010

40. Goldstein H. Multilevel statistical models. London: Edward Arnold; 1995

41. Rabe-Hesketh S, Skrondal A. Multilevel and Longitudinal Modeling Using Stata Third Edition Volume I: Continuous Responses. edn. Texas: Stata Press; 2012.

42. Makkar SR, Turner T, Williamson A, Louviere J, Redman S, Haynes A, Green S, Brennan S. The development of ORACLe: a measure of an organisation's capacity to engage in evidence-informed health policy. Health Res Policy Syst. 2016;14(4)

\section{Submit your next manuscript to BioMed Central and we will help you at every step:}

- We accept pre-submission inquiries

- Our selector tool helps you to find the most relevant journal

- We provide round the clock customer support

- Convenient online submission

- Thorough peer review

- Inclusion in PubMed and all major indexing services

- Maximum visibility for your research

Submit your manuscript at www.biomedcentral.com/submit
) Biomed Central 